\title{
The River
}

\author{
By Toh, Hai Leong
}

Fall 1998 Issue of KINEMA

HE LIU (The River 1997). Tsai Ming-liang. Cast: Lee Kang-sheng, Lu Hsiao-ling, Miao Tien, Yang Kuei-mei, Ann Hui.

Loosely strung together as the last part of a trilogy (the first two being Rebels of the Neon God and Vive l'amour) about dysfunctional families, urban anomie and loveless sex, The River by Malaysian-born, Taiwanese director Tsai Ming-liang is about three protagonists or rather antagonists who do not really relate to one another. All three starred his favourite muse -- Lee Kang-sheng

Xiao Kang (played by Lee Kang-sheng who also starred in the first two features) is a young man who, while wandering aimlessly in central Taipei, gets tricked by into appearing as a corpse in a movie floating in the highly polluted Tansui river. Xiao Kang's father (Miao Tien) is a morose-looking retiree who frequents the city's gay saunas. In one of the film's ironies, he accidentally picks up his own son. Lee's mother is a jaded, middle-aged woman (Lu Hsiao-ling) who works as an elevator attendant with a nondescript lover who deals in pirated porno-videotapes. However it is not until some thirty minutes into the film that we realise these three individuals are related.

After floating down the river, Xiao Kang suddenly develops a pain in his neck and shoulder, an affliction which mysteriously resists all forms of treatment. The quest for a cure makes up the premise of the film. The parents' separate odysseys to the many doctors and healers prove futile and they are frustrated. Then, as in his previous films, Tsai Ming-liang's signature motif of a leaking roof appears here in the father's bedroom. At first, the father uses a pail to solve the problem but when it becomes unmanageable, he deflects it by rigging up a plastic canopy above his bed and directing the water to the drains outside.

As with a Tsai Ming-liang film, the usual motifs -- a dripping roof, the non-communication of city-dwellers, meaningless sex, isolation and alienation -- predominate and threaten to make this film unremittingly gloomy. Fortunately, a kind of black humour is provided in the scenes when the father tries not very successfully in the backseat to hold up his son's tilted head while the latter drives his scooter. In the final analysis, The River can be especially enjoyed by connoisseurs of good Chinese cinema. But you have to plough through the two earlier films Rebels of the Neon God and Vive l'amour to come to a full appreciation of this contemporary masterpiece. You have to look very hard for a cameo appearance by renowned actress Yang Kuei-mei of the 1980s Taiwanese New Wave. Hong Kong filmmaker Ann Hui (The Boat People, The Secret, Song of the Exile, Summer Snow) is easier to spot -- she plays herself at the beginning of the film.

\section{Author Information}

TOH Hai Leong is a Singapore-based freelance film critic and filmmaker (Zombie Dogs, 2005) who writes for independent film publications such as Screen International and World Paper. He has covered the Hong Kong International Film Festival since 1985 and specializes in the cinemas of Hong Kong, Taiwan, China, Korea and Japan. 